\title{
2nd BCS IRSG Symposium: Future Directions in Information Access 2008
}

\author{
London
}

22nd September 2008 


\section{Abstract}

This year's Symposium provided a forum where future directions of information access were presented and discussed in an open and friendly environment. The programme was packed with early career researchers with novel and interesting research ideas which they shared during in interactive sessions throughout the day. 


\section{Preface}

Last year the $1^{\text {st }}$ BCS-IRSG Symposium on Future Directions in Information Access was established to provide a forum for early career researchers to present, share and discussion their research which is at a more formative or tentative stage.

\section{Symposium Aims}

The objectives of the Future Directions in Information Access (FDIA) are:

- To provide an accessible forum for early researchers (particularly PhD students, and researchers new to the field) to share and discuss their research.

- To create and foster formative and tentative research ideas.

- To encourage discussion and debate.

\section{Symposium Themes}

Future directions: to encourage research that focused on the possible paths and further work. Presenting the, what if scenarios, possible solutions, pilot studies, conceptual and theoretical work.

Information Access: to capture the broader ideas of information retrieval, storage and management to include interaction and usage.

\section{FDIA 2008}

These proceedings contain the papers presented at the Second BCS IRSG Symposium on Future Directions in Information Access (FDIA2008), held in London on the 22nd of September 2008 at the BCS London Office. FDIA 2008 was held in conjunction the BCS-IRSG Search Solutions held on the $23^{\text {rd }}$ of September 2008. This year's symposium received eleven submissions of which ten were accepted for publication and presentation. Each submission was reviewed by two senior Information Retrieval researchers who were asked to provide detailed reviews and comments to help steer and guide the research presented. In order to facilitate more reviewing each reviewer was given one or two submissions to review. So we are very grateful to the members of the programme committee for their reviews of the submitted papers and we would like to thank them for their much appreciated effort.

Also, we would like to extend our thanks to the BCS for hosting the event, and in particular, Gemma Liddard, Rachel Browning and Mandy Bauer from BCS for their help and assistance in local organization.

Leif Azzopardi

On Behalf of the Organizers and the BCS-IRSG 


\section{Organizers}

Leif Azzopardi, University of Glasgow

Andy MacFarlane, City University

Murat Yakici, University of Glasgow

Ayse Goker, City University

\section{Programme Chair}

Leif Azzopardi, University of Glasgow

\section{Program Committee}

Alex Bailey, Google

Bettina Berendt, K.U. Leuven

Nick Craswell, Microsoft

Norbert Fuhr, University of Duisburg-Essen

Juan M. Fernandez-Luna, University of Granada

Ayse Goker, City University

Gareth Jones, Dublin City University

Gabriella Kazai, Microsoft Research Cambridge

Udo Kruschwitz, Essex University

David Losada, University of Santiago de Compostela

Monica Landoni, University of Strathclyde

Andy MacFarlane, City University

Massimo Melucci, University of Padua

Michael Oakes, University of Sunderland

Mark Sanderson, University of Sheffield

Dawei Song, Open University

Maarten de Rijke, University of Amsterdam

Stephen Robertson, Microsoft Research Cambridge 
Stefan Rueger, Open University

Ian Ruthven, University of Strathclyde

Jun Wang, University College London

Murat Yakici, University of Glasgow 


\section{Papers:}

Modeling the Evolution of Context in Information Retrieval http://dx.doi.org/10.14236/ewic/FDIA2008.1

Integrating Memory Context into Personal Information Re-finding http://dx.doi.org/10.14236/ewic/FDIA2008.2

Automatically Adapting the Context of an Intranet Query http://dx.doi.org/10.14236/ewic/FDIA2008.3

Towards a better understanding of language model information retrieval http://dx.doi.org/10.14236/ewic/FDIA2008.4

An Investigation into Query Throughput and Load Balance Using Grid IR http://dx.doi.org/10.14236/ewic/FDIA2008.5

Building a Distributed Digital Library System Enhancing the Role of Metadata http://dx.doi.org/10.14236/ewic/FDIA2008.6

Testing a Genre-Enabled Application: A Preliminary Assessment http://dx.doi.org/10.14236/ewic/FDIA2008.7

Children's information retrieval: beyond examining search strategies and interfaces http://dx.doi.org/10.14236/ewic/FDIA2008.8

Management and analysis of chinese database extracted knowledge http://dx.doi.org/10.14236/ewic/FDIA2008.9

Selective Erasers: A Theoretical Framework for Representing Documents Inspired by Quantum Theory http://dx.doi.org/10.14236/ewic/FDIA2008.10 